NBSIR 75-719

\title{
A Compliance Testing System for NILECJ
}

Robert Mills

Law Enforcement Standards Laboratory Center for Consumer Product Technology Institute for Applied Technology National Bureau of Standards

Washington, D. C. 20234

February 1976

Final

Prepared for

National Institute of Law Enforcement and Criminal Justice Law Enforcement Assistance Administration

U.S. Department of Justice

Washington, D. C. 20531 

NBSIR 75-719

\section{A COMPLIANCE TESTING SYSTEM FOR NILECJ}

Robert Mills

Law Enforcement Standards Laboratory Center for Consumer Product Technology Institute for Applied Technology National Bureau of Standards

Washington, D. C. 20234

February 1976

Final

Prepared for

National Institute of Law Enforcement and Criminal Justice Law Enforcement Assistance Administration

U.S. Department of Justice

Washington, D. C. 20531

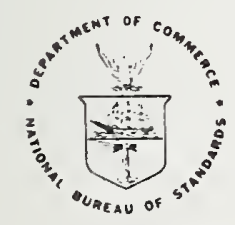

U.S. DEPARTMENT OF COMMERCE, Elliot L. Richardson, Secretary James A. Baker, III, Under Secretary Dr. Betsy Ancker-Johnson, Assistant Secretary for Science and Technology NATIONAL BUREAU OF STANDARDS. Ernest Ambler, Acting Director 
, n w n w

की

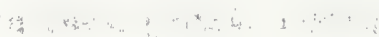


The author is a program manager in the Law Enforcement Standards Laboratory (LESL) of the National Bureau of Standards. This report was prepared under the direction of Jacob J. Diamond, Chief of LESL. It was sponsored by the Advanced Technology Division of the LEAA National Institute of Law Enforcement and Criminal Justice, Lester D. Shubin, Program Manager for Standards. 


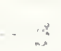


A Compliance Testing System for IILECJ

CONTENTS

Page

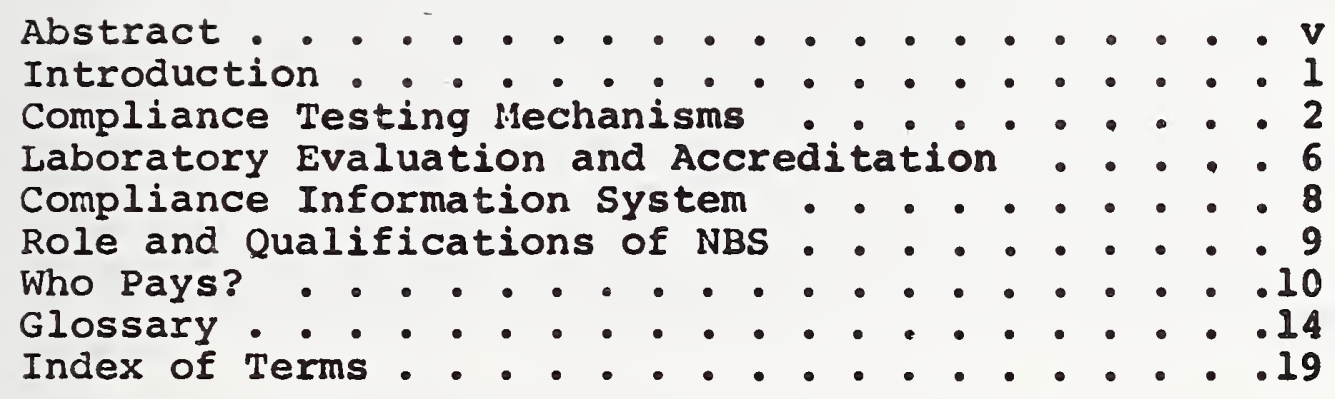





\section{ABS'IRACT'}

In order to assure that NILECJ equipment standards have the impact intended, a Compliance Testing and Laboratory Accreditation program is needed to establish which items available on the market do, in fact, meet the requirements of the standards. This report contains recommendations for such a HILECJ program. In brief, the proposed program would (a) result in a body of qualification and acceptance test data, (b) establish a list of testing laboratories competent to perform these tests, and (c) set up a "compliance information system" for the dissemination of this information to officials in the criminal justice system.

Kiey worcis: Acceptance testing; compliance testing; laboratory evaluation; performance testing; qualified products lists; testing. 


\section{A Compliance Testing System for NILECJ}

\section{INTRODUCTION}

The National Institute of Law Enforcement and Criminal Justice (NILECJ) of the Department of Justice is assisting law enforcement agencies in the procurement and effective use of the best equipment that present technology can offer. One means to that end is the development of performance standards for law enforcement equipment, a task assigned to the Law Enforcement Standards Laboratory (LESL) of the National Bureau of Standards. These performance standards can be referenced in purchase documents; they serve as objective descriptions of what the user wants and what the supplier agrees to give him. They can also help guide manufacturers in the design of equipment of high utility.

The development and dissemination of standards, however, are only steps in the procurement process. The ultimate benefits to the law enforcement community, to the public, and to the manufacturers cannot be realized until a means is established to ascertain which hardware available on the market does, in fact, meet the requirements of the standards.

Lester C. Thurow, professor of economics and management at the Massachusetts Institute of Technology, has written of this need in a private communication.

"Without testing and inspection, there is the classic economic problem of bad money driving out good. io obtain an order, a company must submit the lowest bid. One of the easiest ways to submit a lower bid is to lower the quality of the equipment being sold. The initial quality cuts are small, but competitive pressures force an escalation of this process until the equipment no longer provides the services desired.

"With simple goods this problern can be avoided, since the customer can quickly determine that he is being sold a good without the cesired performance characteristic. With complicated equipment, there is no simple or easy way to determine whether the good is up to standards. To know whether the equipment is good or bad requires technical testing, both initially to insure that equipment can meet performance standards and subsequently to insure that it does. 
"This testing is in the long-run interest of manufacturers (although it may not be in the interest of any particular manufacturer) since it allows high quality equipment manufacturers to stay in business. Without testing, they will be forced to lower quality standards by the competitive pressures of the market place or go out of business."

'ihis report makes recommendations to NILECJ for the establishment of a compliance testing system for equipment used by the criminal justice system. This "Compliance Testing System" would (a) make available to law enforcement officials impartial information concerning compliance with NILECJ standarás, and (b) enable manufacturers to avoid the time and expense of convincing individually hundreds of police departments that their products are capable of satisfying minimum performance requirements.

\section{Compliance* Testing Mechanisms}

There are several alternatives, not necessarily exclusive of one another, for ascertaining the compliance of law enforcement equipment with the iillECJ standards. First, some larger police departments have test and evaluation divisions responsible for determining the utility of new products. However, most departments do not have in-house capabilities for performing compliance tests in accordance with the IJILECJ standards.

Secondly, inspectors can monitor the manufacturing process at the plant. This "on-site inspection" can be used to monitor quality control. It is being used for some food inspection and military procurement programs, but it is expensive and is not considered to be a viable alternative for NILECJ.

Thirdly, manufacturers can be asked to certify that their equipment meets the requirements of the appropriate standard, and be held legally accountable for their certification. However, reliance solely on manufacturer certification generally is not satisfactory. Since transgressions must be rearessed after the fact, usually by time-consuming court action, there is little protection against companies that have no reputation to uphold and are able to go out of business after a short period of operation. Even for more reputable companies, the pressure of realizing a profit too frequently tempts manufacturers into compromises of product quality if

\footnotetext{
*These and other terms relating to product standards, procuct testing and laboratory accreditation are defined in the glossary on pages 13 to 18 .
} 
routine independent checks are not made. See, for example, "The Aircraft Brake Scandal," in the April 1972 issue of Harper Magazine, which relates a tale of falsified laboratory test results and fraudulent claims by a manufacturer having trouble fulfilling a government contract. Manufacturers may of course do their own product testing. This certainly should be encouraged, as long as the results are intended primarily for the manufacturer's own use.

Another approach is to have the product manufacturer certify and an independent testing laboratory verify. In this way, the manufacturer retains the legal responsibility for the quality of his product. Once the product is found by the testing laboratory to be in compliance with the appropriate standard, the name of both the product and its manufacturer can be placed on a qualified products list (QPL). As long as his product remains on the published QPL, the manufacturer is obligated to make that product in compliance with the product standard.

Two types of product compliance testing are of interest. Product qualification tests are performed in advance of and independent of any specific procurement action, for the purpose of establishing a QPL. The fact that a product has been tested and placed on a QPL means that the particular model meets the requirements of the standard. The inclusion of a product on a QPI does not, however, guarantee the acceptability of every individual lot or shipment. This assurance can be obtained from product acceptance tests, which are performed to determine the acceptability of delivered items which have been purchased under a contract requiring compliance with the appropriate standard.

The Compliance Testing System must be based on technical competence and integrity if it is to enjoy any significant degree of acceptance. For example, the testing laboratories must be independent laboratories. Independent laboratories can be commercial testing laboratories (there are several thousand in the United States), non-profit institution labcratories, government laboratories, or university laboratories. By definition, an independent laboratory cannot be connected with the manufacturer of the product, cannot be involved in the promotion of the product, and cannot have an inordinate (for purposes considered here, greater than 10 percent) amount of its income derived from a company which manufactures a product 
of the type under test. $\Lambda$ corporate or captive laboratory which is controlled by a manufacturer or distributor is obviously not an unbiased, independent laboratory, even though it may be a very competent one; however, the laboratory accreditation program described later can benefit captive as well as independent laboratories.

Other safeguards could readily be incorporated into the program. Renewal qualification tests will be required, to assure that changes in product design have not been made, either intentionally or unintentionally. When possible, manufacturers should be required to select different testing laboratories for the original and the renewal qualification testing of a product. In addition, the results of any acceptance tests of a given product could be compared for consistency with the qualification test results. Products for which comparatively large amounts of acceptance test results were available should require less frequent renewal testing to stay on the QPL than those products for which few acceptance test data were available.

The samples tested in qualification tests must be representative of those produced in production runs. If sales volume is large enough, this is best accomplished by having the samples purchased anonymously through a regular retail supplier. However, purchasing the test samples may, in some cases, add significantly to the cost of the compliance testing. There may also be some legal obligation to purchase and test all available brands. This could lead to difficulties; conceivably, a manufacturer could insist that IILECJ purchase a product which obviously would not meet the requirements of the standard, and he could demand an exorbitant price.

An alternative is to invite all manufacturers of law enforcement equipment for which IiILECJ standards have been promulgated to submit their products for qualification testing. lianufacturers would be required to certify that the submitted products were representative of their production in all significant respects. Significant differences between qualification and acceptance test results would then indicate a violation of that product's certification or trouble with one of the testing laboratories, either of which would require remedial action. 
The methods used for qualification and acceptance testing must be identical. lowever, economic considerations may dictate that acceptance testing be less thorough than qualification testing. In that case, the methods for acceptance testing might consist of a subset of the test methods for qualification testing. LESL could recommend the appropriate subset. More than one subset may have to be available to accommodate different local economic circumstances. LISI should make certain that the purchaser is properly advised by the qualified testing laboratory of the reduced quality assurance to be expected for a given subset of test methods. Advice shoulä also be available concerning appropriate sampling plans.

Copies of all test reports from participating laboratories should be submitted to the compliance program administrators, whether the items under test pass or fail. This procedure will preclude reporting only successful test results, and will prevent a manufacturer from repeatedly having an unacceptable product tested until, by the laws of probability, it is eventually passed. To guard against incomplete information being sent, the complete laboratory job file should be open to inspection by the program administrators.

The possibility of authorizing product manufacturers to affix a IIILECJ label or logo to products listed on a QPL has been considered. Use of such a logo would have value in bringing the NILECJ Lquipment Program to the attention of law enforcement officials. Ilowever, the use of a logo does have the following disadvantages:

(a) A product may be tested and found acceptable for one application, but not another. For example, a particular police helmet may give satisfactory protection as a motorcycle crash helmet, but not as a ballistic helmet. Specific product certification cannot be communicated with a logo as it can be with a QPL. A user who sees the logo but does not check the QPL can develop an unjustified confidence in the utility of his equipment. Careful labeling could minimize this problem.

(b) Logos are usually intended for equipment that has passed qualification tests. A logo may, however, lead a user to assume that an item has passed both qualification and 
acceptance tests. 'Ihat is, he may improperly assume that the logo guarantees the quality of the shipment he receives.

(c) Comparatively speaking, potential enforcement problems for QPL's should be smaller than for logos. That is, entries on a QPL would clearly be under the control of NILECJ, but there may be difficulties in forcing a manufacturer to stop affixing the logo to products which no longer comply with the standard, or in neutralizing the logo on those already in distribution. There is, of course, the similar problem involved in assuring that a procurement decision is based on a current, not an obsolete, QPL.

\section{Laboratory Lvaluation and Accreditation}

Testing laboratories other than NBS will have to be involved with compliance testing. Accreditation of these testing laboratories will be an important part of the

Compliance Testing system. Only accredited laboratories should be eligible for selection to perform qualification testing, and only accredited laboratories should be recommended to police officials who are selecting a laboratory for acceptance testing.

Laboratory accreditation should be distinguished from laboratory certification. Certification implies a warranty or guarantee of a laboratory's performance. There is no valid approach to examining a laboratory so that guarantees of future performance can be issued. Accreditation resulting from laboratory evaluation does not ensure the quality of future output. Rather, it indicates that there is no apparent reason why the laboratory cannot perform a function adequately. The only realistic goal of laboratory evaluation is accreditation, not certification. However, laboratory performance can be monitored after the initial accreditation (a) by comparing data sent to the Compliance Information System from different laboratories testing the same product, (b) via occasional unannounced examinations of accredited laboratories and (c) by requiring that accreditation be renewed every few years. Laboratory accreditation can be revoked in cases of misrepresentation of information or unsatisfactory performance.

Accreditation would be granted for those testing functions of laboratories that meet pre-stated criteria. These criteria will, for the most part, relate to the methods of test in 
specific iIllic stanciaris, although some criteria such as riaragerial inciepencience fror lianufacturers anà venciors anci records keeping will have general applicability. 'ihe Iraw inforcement standaras Laboratory at the National bureau of Standarcis is currently developing laboratory evaluation criteria for the first few performance standaras promulgated by iILECJ.

Laboratory accreditation criteria and evaluations can be classified as either performance-based or non-performancebased. Lion-performance-based criteria can relate, for example, to the cleanliness of laboratory equipnent or facilities, or to the academic backgrouncis of persomnel. Performance-based criteria, on the other nand, relate to the actual results of tests on controlled samples by the laboratory under examination.

The objective of non-performance-basea evaluation is to predict performance. Since performance-based evaluations are inlierently more direct, they will be used to the greatest extent practical.

Laboratory accreditation criteria can also be classified as either teclinical or nontechnical. riechnical evaluations of testing laboratories are made to determine if they have the capacity to carry out properly the tests specified in the proauct performance standards. Nontechnical evaluations which are also appropriate and have been mentioned earlier are rilanagerial incepenäence from manufacturers anci venciors, and records keeping. Another nontechnical criterion which nay be relevant concerns equal employnient opportunity (ILO) at the testing laboratories. The relevance of this criterion is a policy cuestion best answered by IrILLCJ.

rille checking of laboratories to determine whether the prestated criteria are satisfied can be considered to be a thireestep prccess--examination ana evaluation by LISSL followed, if neriteci, by iILICJ accrecitation. Isaboratory examinations provicle the information upon whicl laboratory evaluations are made, which in turn serve as the basis for IiLSI,'s reccrmenciation to iILICJ for laboratory accrecitation. On-site examinations at the laboratorics are expersive ir terms of requirea travel ari marpower. io the extent practical, axaminations will involve the laboratories in question sencing information to Lisil for evaluation. icwever, a few on-site 
examinations will have to be macie, some on an unannounceu basis, to check the information furnished by the laboratories.

Laboratories will be evaluated and accredited on a standard-by-stanciard basis. Isolation of the specific causes of problems being experienced by laboratories failing to meet certain performance criteria will be outsicie the scope of this program unless a problen is widespread among testing laboratories involved with the compliance 'lesting system, or the basis for the problem can be established with very minor effort.

\section{Compliance Information System}

A "Compliance Information systen" is needed as part of the compliance lesting system for the purpose of eliciting information concerning the performance of devices listed on the liIllCJ ciualified products lists. Reports will be tabulated from laboratories performing qualification and/or acceptance testing. cooperation in supplying this information will be a concition for being an accredited laboratory. In addition, field performance data will be solicited from law enforcement agencies using the equiprient covered by ivIIECJ standarcis.

I'he Compliance Information system will help to assure that (a) equipment listed on a ijILlCJ qualifieci products list continues to perform in accordance with the requirements of the IIILECJ standara, (b) experience in field use coes not indicate an excessive breakdown rate or the existence of maintenance problems, (c) any need for revision of the standard is recognized, and (d) problems in the performance of any of the testing laboratories are recognizec. When tabulated information indicates the need, a special investigation will be macie. If, for example, it is cietermined that a manufacturer has a quality control problem, continued listing of his product on the QPL will be reviewed. If an excessive field breakdown or maintenarice problem is found, either the prociuct will be removed from the QPL or the applicable standard will be revised, as appropriate. If a problem in testing laboratory performance is found, the continued accreditation of that laboratory will be reviewed.

ilue National Highway "rraffic Safety Administration (NIISA), Departnent of iransportation, announced in the ilovember 5 , 1973, issue of the Federal Register, page 30159, the 
establishment of a program having a standards Compliance Information System and many other features similar to those recommended for the NILECJ Compliance Testing System. The NHTSA Compliance Testing system was planned with NBS/LESL consultation; the breath alcohol testing equipment performance standards for which it was established are being developed for NHISA by LESL. It should be noted that only equipment on the INHTSA qualified products list may be purchased with INHTSA funds - a policy which NILECJ may also wish to adopt.

\section{Role and Qualifications of NBS}

The large amount of both product qualification and acceptance testing necessitates the involvement of testing laboratories other than NBS. NBS/LESL's role is in the development of the standards, it the arbitration--if needed--of any disputes which may arise concerning compliance test results, and in the management of the compliance testing system, but not in compliance testing per se. All of these activities will of course be under the direction of INILECJ.

Each QPL will be a NILECJ document. Its content will be based largely on the information obtained from the Compliance Testing system. Likewise, the official list of accredited laboratories will be a NILECJ document, although the accreditations will be based on evaluations performed by INBS/LESL.

INBS has had and continues to have considerable involvement with laboratory evaluations. Current NBS projects involving laboratory evaluation relate to the testing of cement and concrete, paper and paper boxes, rubber, color and appearance, mobile homes, mass standards, state metrology laboratories, clinical chemistry and toxicology. A special Laboratory Performance Technology Section has been established at NBS. NBS management, together with other officials in the U.S. Department of Commerce, are planning with industry and professional associations the establishment of a national system for laboratory evaluation; several public hearings have been held on the subject at NBS. 
Although wijs has almost no regulatory authority, it has established a reputation of Leing a fair and careful arbitrator il cisputes involving measurement. Members of the liss staff liave been among the vanguara in the development of improved techniques for laboratory evaluation. in Association of ufficial Analytical Chemists publication, "Statistical lechniques for Collaborative mests," was written by an IIBS statistician, Dr. W. J. Youden. Chapter three of illis special publication 300 titleci "Interlaboratory iests" is a collection of papers on the subject by iJBs authors. The ecitor of the "AS"M bulletin" included the following quotation in his introductory remarks to a paper about interlaboratory testing by two IDS scientists: "rhis paper gives a very complete treatment of the problem which almost every ASTM committee is constantly trying to solve.. (it is) a more comprehensive approach to the problem of ciesigning and interpreting interlaboratory studies than has appeared in the literature up to now." (ASTM Bulletin, July 1959, page 53).

During the development of performance standards, IISSI must do a certain amount of product testing to determine current performance levels. This work is rarcly sufficient to regate the need for qualification tests after promulgation of the standard, lut pertinent test results obtained during the development of the standard should certainly be utilized by the Compliance 'i'esting system. Conversely, the compliance test results will serve as early incicators that particular [jIILCJ standards shoulà be consiciered for revision. Thus, close liaison between the standards cievelopment program and the Compliance resting Program will be essential. 'lhis two-way flow of information will be enhanceci by both programs being within LESL.

\section{Who Pays?}

hivo sinoulc pay the costs of a riational compliance testing system for law enforcoment equipment? Iet us consider separatcly cach of the colmponent parts of a complete, comprehensive system.

Laboratory livaluation and Accreaitation

In and of itself, a laboratory evaluation and accreditation program is of no valuo. Such a prograr: is, however, central to any conplialıe testing syster, no natter how simple or complex, 
large or small. Fone of the other possible components of sucl. a system can functior: without the availability of testing laboratorics whose test resulls are accepted by both tho buycr and seller. rhese consicierations uncerly the guestion of vho should ray for laboratory evaluation and accreaitation.

Ir a mature, functioning compliance testing systeri, we recolwiend that nost, if not all, of the full pro-rata cost of evaluating and accreciiting a testing laboratory be borne by tilat lavoratory itself. In a competitive environment, this woulc! assure that accrecitation woulc be sought by only those tosting laboratories to whom it was financially attractive. clearly, this woulci be tie most cost-effective and equitable arrangement.

In starting up such a program, however, when it is not clear how much testirg business will be generated, and who the customers will be, it woulc be unreasonable and unrealistic to expect the testing laboratories to bear the costs of their evaluation and accreditation, plus the program start-up costs. It is reconunencieu that the sponsor of the program, ijIlicJ, pay the major portion or all of these costs, in order to yet the prograri uriuer way and to attract as many testing laboratories as possible into the program. It is further recommencied that the proportion of the costs borne by the testing laboratories themselves be increased gradually, but as rapidly as; the circumstances warrant, until the program is fully selfsupporting, or nearly so. It must be realized that, for each equipment iten in the program, at least onc testing laboratory must obtair enough business to justify its cost of obtaining and maintaining accreaitation. To assure this, some continuing ivillcu subsidy may be required, in particular cases.

\section{Fanufacturer Certification Based on Accredited Laboratory Testing}

Uncier this systern option, once one or more testing laboratories are accredited to test an equiprnent item in accordance with the appropriate NILLCJ standard, any and all manufacturers of that item would be free to contract incividually with the accredited testing laboratory of their choice, at a fee agreed to by them, to have their products tested for compliance. Ihe manufacturers coula use these test results in their advertising anc/or marketing, could use them as a basis for certifying that their products complied with the 
appropriate standaru, anci could therefore bid on procurement contracts that required compliance with the IIILCJ standard.

While some rationale exists for HILECJ financial support of this progralu option, no simple means is envisioned for cioing so. It is therefore recommended that payment for services unier this program be fully borne by the individual malufacturer or aistributor. The operation of this syster: woula involve little or no Government participation; it woula probably be little used if Qualified prociucts Lists were establisheci (see below).

\section{Routine Icceptance I'esting}

One of the options available to a purchaser, after he lias receivea a shipment of material claimec to comply with the requirerients of a iIILCJ standard, is to verify its compliance by having the shipment tested by a qualified testing laboratory. Where such acceptance testing is desirea, it should be performec on a fee-for-service basis, entirely paid for by the purcinaser and/or by the supplier, in accordance with the requirement of their purchasc agrement.

It is recormencied that the states and local jurisdictions we authorized anci encouraged, but not required, to pay for such acceptarice tests with LIn block-grant or other INA funds allocated to them. rhis authorization should govern whether or not the equipment itself is paici for with Irin funcis.

\section{Qualified Frociucts Iists}

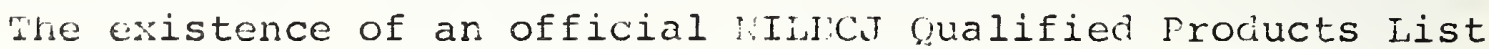
for a particular equipment iten woulc. rake it very easy for a purchaser to acquire NIIICJ-Stancarc equipment. In sorie cases, such as wher the cost of testing was large coinpared to the cost of the shipment, reference to a glPI would be perhaps the only way in will an objective, cost-effective purchase could be macie.

The establislment anci riaintenance of a @PL for each appropriate cquipment item is thus a major tool whercby !:IJ,LCJ colic assure the quality of equiplient procured by state anci local agencies. Similarly, the listing of its procluct on a WIIECJ \PL could ve of substantial economic benefit to an equipment manufacturer. Joint funding of a OPL by I:IIICJ and the interested manufacturers is therefore warranted, and is recommended.

is ?PL program shoula be run by LEAA/UIT.SCJ itself, or on its behalf by another public agency. 


\section{GLOSSARY}

This Glossary is intended to assist the reader understand the terminology by comparing and contrasting related terms. The entries are grouped into three sections relating to the subject areas of product standards, product evaluation and laboratory accreditation. Related entries within each section are also grouped rather than listed alphabetically. However, an alphabetical listing of entries is more convenient for locating the definition of a specific term. Hence, a separate Index of Terms is included at the back of the Glossary.

Many of the definitions in this Glossary are based on definitions in an unpublished document drafted earlier at NBS. Some terms in that document are included in this glossary even though they are not used in this report concerning compliance testing. Terms such as, "mandatory standard", "quasi-mandatory standard", and "consensus standard" are of general interest to people working with standards and thus were included in this Glossary. 


\subsection{STANDARD}

A prescribed set of conditions or requirements--the physical, functional, performance, or conformance characteristic thereof--to be satisfied by a product. Standards included under this definition are called product standards or engineering standards.

\section{1 .1 VOLUNTARY STANDARD}

A standard with which there is no obligation to comply. A voluntary standard may become a quasi-mandatory standard, mandatory standard, code, regulation, or rule as a result of utilization or adoption by a regulatory authority.

\subsubsection{QUASI-MANDATORY STANDARD}

A standard with which there is no legal obligation to comply, but which is required in practice or under certain conditions, such as a requirement of a marketplace or compatibility with other products.

\subsubsection{MANDATORY STANDARD}

A standard with which there is an obligation to comply by virtue of an action by government or by an authority endowed with the necessary legal power; called a code, regulation, or rule.

\subsubsection{CONSENSUS STAINDARD}

A standard for which there is general agreement among those affected by the standard that the prescribed set of conditions and requirements are technically sound and meet the needs prevailing at that time.

\subsubsection{PERFORMANCE STANDARD}

A standard which prescribes the acceptable functional or operational characteristics of a material, product or system in accordance with the use to which the performance would apply; includes or references the test methods by which these characteristics are measured. 


\subsubsection{DESIGN STANDARD}

A standard which describes the required physical or dimensional characteristics of a product or system and, in some cases, its manufacture, construction or fabrication.

\section{1 .7 IILECJ STANDARD}

A voluntary standard developed by the Law Enforcement Standards Laboratory at the ivational bureau of Standards and promulgated by the National Institute of Law Enforcement and Criminal Justice (NILECJ), U.S. Department of Justice, for equipment used in law enforcement, crime deterrence, or criminal justice activities. NILECJ standards are technical documents consisting of performance and other requirements together with a description of test methods.

\subsection{TEST METHOD}

A description of the test procedures, equipment and methodology for testing a material or product in determining its conformance to a standard or other set of conditions and requirements.

\subsection{REFERENCE MATERIAL}

A material, substance, or device whose intrinsic properties are used for physical comparison (e.g., an INBS Standard Reference Material (SRM) which is a well characterized and certified material produced in quantity and used to develop reference methods of analysis and tests and to calibrate measurement systems), sometimes referred to as a standard.

\section{PRODUCT EVALUATION}

\subsection{PRODUCT COMPLIANCE TEST}

A test to determinate the design or performance characteristics of products for the purpose of establishing their conformance with the requirements of applicable standards, codes or other requirements. 


\subsubsection{PRODUCT' ACCEPTANCE TEST}

A compliance test to determine the acceptability of delivered items which have been purchased under a contract requiring compliance with the appropriate standard, code, or other requirement.

\subsubsection{PRODUCT QUAIIFICATION TEST}

A compliance test performed in advance of and independent of any specific procurement action, for the purpose of establishing a qualified products list or authorizing the use of a logo.

\subsection{QUALIFIED PRODUCTS LIST (QPL)}

A list of products, and their manufacturer, which have been tested and found to comply with the requirements of applicable standards, codes or other requirements.

\subsection{LOGO}

A symbol, label, hallmark or statement authorized by a certification agency for affixing to a product indicating that the product is in conformance with specified provisions of the applicable standard, code or other requirement.

\section{LABORATORY ACCREDITATION}

\subsection{ACCREDITATIOIN}

The act of giving official recognition of specific qualifications. Accreditation of a laboratory indicates that there is no apparent reason why the laboratory cannot perform a function adequately. It does not guarantee the quality of future performance.

\subsection{CERTIFICATION}

The act of giving an official warranty or guarantee of performance. There is no valid approach to examining a laboratory for laboratory certification because guarantees of future performance cannot be made.

\subsection{TESTING LABORATORY}

A place equipped and staffed to conduct product tests including product compliance tests. 
A testing laboratory which has no organizational tie or financial interest in a manufacturer, vendor, or the promotion of a specific product on which tests are performed. It has sufficient breath of activity so that the loss or award of a specific contract for test services would not be a substantive factor in the financial well-being of the laboratory. It may offer test services under contract or on a fee basis, and may be a profit or non-profit organization.

\subsubsection{CORPORAIE OR CAPTIVE TESTIIVG IABORATORY}

A testing laboratory organizationally affiliated with a product manufacturer or vendor.

\section{4 LABORATORY EXAMINATION}

The process of obtaining information in order to judge the laboratory's capability for performing specified product tests, e.g., product compliance tests. Laboratory examinations provide information upon which laboratory evaluations are made. Laboratory examinations can involve on-site and remote activities; the remote activities involve the laboratories sending information to the evaluation agency.

\subsection{LABORATORY EVALUATION}

The decision making process, using information from laboratory examinations, upon which laboratory accreditation-or a recommendation for laboratory accreditation--is based.

\subsubsection{IABORATORY EVALUATION CRITERIA}

Statements prescribing the organizational and technical resources, the equipment and facilities, the operational procedures, and the minimum technical performance levels required of a testing laboratory for accreditation.

\subsection{COLLABORATIVE REFERENCE TESTING}

A program or system in which a uniform material or product, properly randomized or of controlled characteristics, is distributed to participating laboratories. The laboratories test the material or product and submit the test results to the agency administering the collaborative test for evaluation. Collaborative reference testing may be used voluntarily by testing laboratories for self-evaluating or improving test criteria and methodology. In conjunction with other procedures, collaborative reference testing may be used in laboratory examination for accreditation or continued accreditation. 
INDEX OF TERMS

Section

Accreditation ............ . . . . . . .

Certification . . . . . . . . . . . . .3.2

Collaborative Reference Testing . . . . . 3.6

Consensus Standard . . . . . . . . . . .1.1.4

Corporate or Captive Testing Laboratory . .3.3.2

Design Standard . . . . . . . . . . .1.1.6

Independent Testing Laboratory . . . . . 3.3.1

Laboratory Accreditation . . . . . . . . 3

Laboratory Evaluation . . . . . . . . .3.5

Laboratory Evaluation Criteria . . . . . .3.5.1

Laboratory Examination . . . . . . . . 3.4

Laboratory Examination Methodology . . . .3.4.1

Logo . . . . . . . . . . . . . . . 2.3

Mandatory standard . . . . . . . . .1.1.3

NILECJ Standard . . . . . . . . . . .1.1.7

Performance standard . . . . . . . .1.1.5

Product Acceptance Test . . . . . . . .2.1.1

Product Compliance Test . . . . . . . . .2.1

Product Evaluation . . . . . . . . . . . 2

Product Qualification Test . . . . . . .2.1.2

Product Standards . . . . . . . . . . . I

Qualified Products List (QPL) . . . . . . .2.2

Quasi-Mandatory Standard . . . . . . . .1.1.2

Reference Material . . . . . . . . . .1.3

Standard . . . . . . . . . . . . .1.1

Testing Laboratory . . . . . . . . . .3.3

Test Method . . . . . . . . . . . .1.2

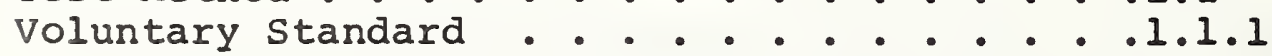


NBS-114A (REV.7.73)

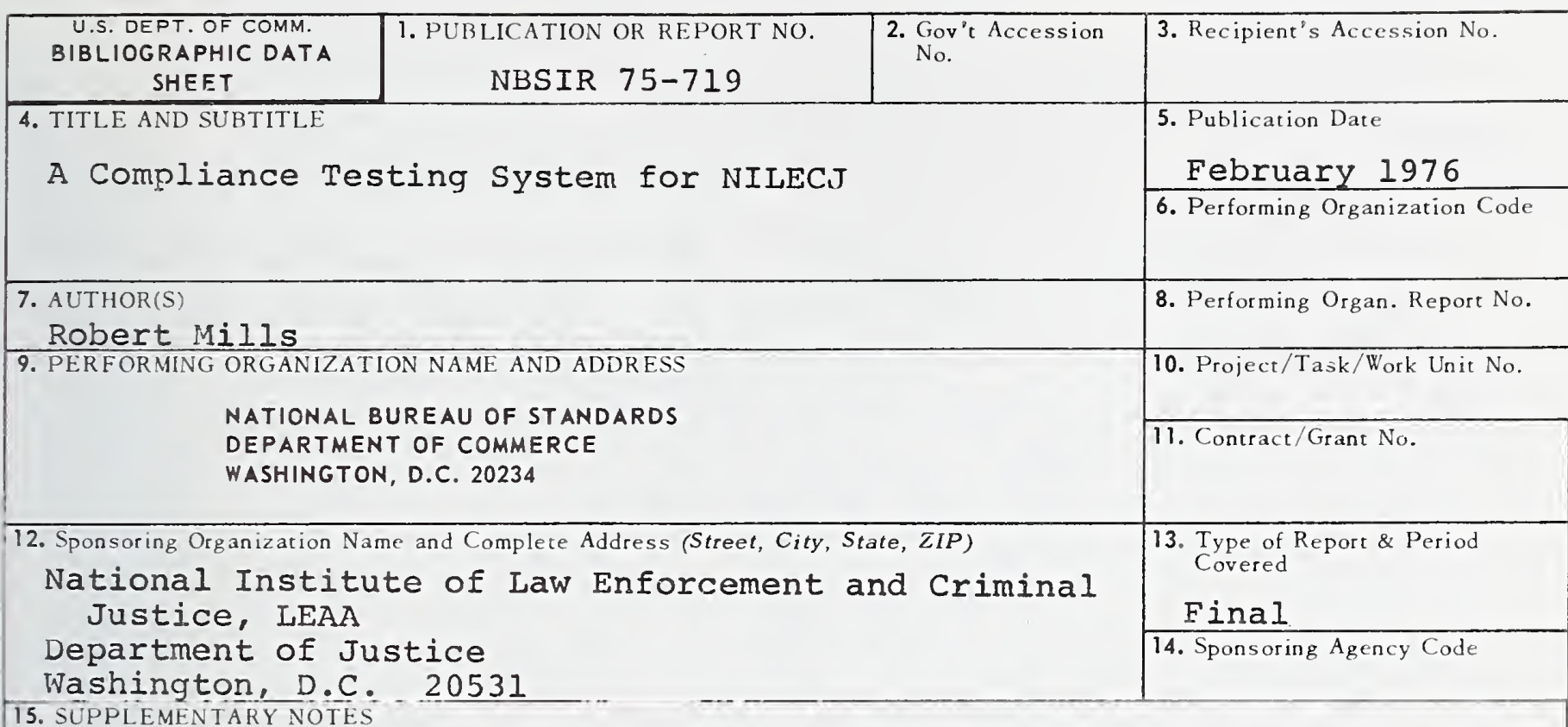

15. SUPPLEMENTARY NOTES

16. ABSTRACT (A 200-word or less factual summary of most significant information. If document includes a significant bibliography or literature survey, mention it here.)

In order to assure that NILECJ equipment standards have the impact intended, a Compliance Testing and Laboratory Accreditation program is needed to establish which items available on the market do, in fact, meet the requirements of the standards. This report contains recommendations for such a NILECJ program. In brief, the proposed program would (a) result in a body of qualification and acceptance test data, (b) establish a list of testing laboratories competent to perform these tests, and (c) set up a "compliance information system" for the dissemination of this information to officials in the criminal justice system.

17. KEY WORDS (six to twelve entries; alphabetical order; capitalize only the first letter of the first key word unless a proper name; separated by semicolons) Acceptance testing; compliance testing; laboratory evaluation; performance testing; qualified products lists; testing.

18. AVAILABILITY

$$
\text { X Unlimited }
$$

For Official Distribution. Do Not Release to NTIS

Order From Sup. of Doc., U.S. Government Printing Office

Washington, D.C. 20402 , SD Cat. No.C13

X $\urcorner$ Order From National Technical Information Service (NTIS) Springfield, Virginia 22151

\begin{tabular}{|l|c|}
\hline $\begin{array}{l}\text { 19. SECURITY CLASS } \\
\text { (THIS REPURT) }\end{array}$ & 21. NO. OF PAGES \\
UNCL ASSIF IED & 24 \\
\hline $\begin{array}{l}\text { 20. SECURITY CLASS } \\
\text { (THIS PAGE) }\end{array}$ & 22. Price \\
UNCLASSIFIED & 3.50 \\
\hline
\end{tabular}


